\title{
ESTUDO DA VARIABILIDADE GENÉTICA DA PROTEINA LACTOFERRINA EM UMA AMOSTRA DA POPULAÇÃO EURO-BRASILEIRA
}

\author{
Genetic variability study of the lactoferrin protein in \\ an euro-brazilian population sample
}

\author{
Antunes Alessandra Armstrong ${ }^{1,3}$ \\ Maria Fernanda Lahr Vasconcellos Sampaio ${ }^{2,3}$ \\ Giovanna Canezin Galletto ${ }^{2,3}$ \\ Fábio Rueda Faucz ${ }^{3}$
}

\section{Resumo}

A lactoferrina (LF) é uma glicoproteína que pertencente a uma família de proteínas conhecida como transferrinas, que se caracteriza pela forte afinidade com os íons de ferro livres no organismo. Tem propriedades antiinflamatórias, antifúngica, bactericida, bacteriostática, atuando contra a ação microbiana no organismo humano. Sua atuação pode ser de forma bacteriostática e, algumas vezes, bactericida. $\mathrm{O}$ gene da LF se encontra na região cromossômica 3q21-q23. A seqüência analisada está presente no primeiro éxon. Realizaram-se no total 529 testes, contendo 427 amostras de indivíduos mais 102 repetições, submetidos às etapas de PCR e SSCP. Do total de amostras observadas apenas 52 apresentaram amplificação. Embora 0 espaço amostral final tenha sido significantemente menor que 0 inicial, puderam ser observados 4 padrões diferentes, por SSCP.

Palavras-chave: Lactoferrina; Variabilidade genética.

\section{Abstract}

The Lactoferrin $(\mathrm{LF})$, or Lactotransferrin, is one cationic glicoprotein, which belongs the transferrin's family. This group is characterized for iron's ions affinity. The gene LF is finding in chromosome 3 (3q21-q23). This protein has anti-inflammatory, bactericidal, bacteriostatic and antifungal property, act against the microbial action. The sequence analyzed is present in first exon. It were realized 529 tests, in total the 427 persons more 102 repetitions. This samples were submitted in technical of PCR, and SSCP, where were analyzed only 52 amplifications. Although only fell samples were amplified, four different standards were observed.

Keywords: Lactoferrin; Genetics variability.

Bióloga, Mestranda em Ciências da Saúde da PUCPR. E-mail: aleantunes_a@yahoo.com.br

Aluna de Graduação em Biologia pela PUCPR.

Laboratório de Genética Molecular, Pontifícia Universidade Católica do Paraná - PUCPR, Curitiba - PR 


\section{Introdução}

A lactoferrina (LT) é uma glicoproteína $(1,2,3)$ que pertence à família das transferrinas (4). É encontrada em baixas concentrações no soro humano e em grandes concentrações nas secreções das mucosas $(9-14 \mathrm{mg} / \mathrm{ml})$ (5). Caracterizada pela forte afinidade com íons de ferro livre no organismo $(5,6,7)$, desempenha um mecanismo de imunidade não específica, inibindo o crescimento de microorganismos $(2,6)$.

É reconhecida a atividade antimicrobiana da LT $(1,3,4,5,6,7,8,9,10,11)$, atuando de forma bacteriostática e/ ou bactericida pela quelação do ferro $(2,3,5,8,12)$, limitando a quantidade de íons no meio, essenciais para o crescimento bacteriano $(2,5,6,13)$. São descritas atividades antifúngicas, antitumores, antivirais (2) e antinflamatórias $(2,4)$. O seu papel na resposta inflamatória ocorre por sua presença em grânulos de neutrófilos $(3,4,5,9,10)$

O gene da LF se encontra no cromossomo 3 na região 3q21-q23 (14). Apresenta peso molecular igual a $80 \mathrm{kDa}(2)$. Estruturalmente a $\mathrm{LF}$ apresenta dois lobos globulares conectados entre si $(2,15,16)$, desempenhando uma interação cooperativa (15). Cada lobo é subdividido em dois domínios de tamanhos iguais. Um lobo é sobreposto ao outro por uma rotação de $180^{\circ}$ (16).

Os sítios de ferro estão presentes nos dois lobos e em ambos apresentam a mesma localização. Devido o local onde se encontram, é necessário, para garantir a sua abertura ou fechamento, que ocorra uma mudança conformacional nos dois aminoácidos presentes na coluna da cadeia. (16).

Os átomos de ferro são coordenados na estrutura da LF por 4 aminoácidos ligantes da proteína - Tyr-93, Tyr-191, His-252 e Asp-61, que se apresentam distribuídos em três partes distintas da estrutura. A Asp-61 no corpo do domínio I, a Tyr-191 no corpo do domínio II e a His-252 e a Tyr-93 na coluna da cadeia, por onde passam os íons de ferro (16).

São inúmeras as enfermidades evitadas pela presença da LF no organismo humano, mostrando a importância de se estudar as possíveis variabilidades genéticas, fornecendo subsídios futuros para relacioná-las com doenças.

\section{Materias e Métodos}

A pesquisa foi realizada na Pontifícia Universidade Católica do Paraná - Campus Curitiba,
Centro de Ciências Biológicas e da Saúde, Laboratório de Genética, durante o período de setembro de 2003 a maio de 2004. Neste intervalo foram realizadas as análises de 529 testes, totalizando 427 indivíduos mais 102 repetições.

\section{As Amostras}

Para a realização dos estudos, foram utilizadas amostras de DNA de indivíduos euro-brasileiros escolhidos aleatoriamente. Os doadores estiveram restritos à cidade de Curitiba e identificados como descendentes de populações européias.

As 427 amostras de DNA analisadas foram cedidas pela Pontifícia Universidade Católica do Paraná, 57 foram adquiridas pela metodologia de salting-out e 370 acondicionadas em papel filtro, segundo a metodologia descrita por Raskin e colaboradores (17).

\section{PCR (Reação em Cadeia da Polimera se)}

O DNA foi amplificado por PCR com o conjunto de primers 5'-CTAGTGGGAGAGAAAGAAC e 5' GGACACAGGGACCAAAGC, hibridizando uma seqüência de $402 \mathrm{bp}$, localizada no primeiro éxon do cromossomo 3 da LT. Os reagentes utilizados foram $50 \mathrm{pmol}$ de cada primer, $20 \mathrm{mM}$ Tris- $\mathrm{HCl}$ ( $\mathrm{pH}$ 8,4), $50 \mathrm{mM} \mathrm{KCl}, 1.5 \mathrm{mM} \mathrm{MgCl}{ }_{2}, 0.2 \mathrm{mM}$ DNTPs e $2.5 \mathrm{U} / \mathrm{ul}$ de TaqDNA polimerase. Quarenta ciclos de PCR seguiram tais condições: desnaturação a $94^{\circ} \mathrm{C}$ por 1 minuto, anelamento a $50^{\circ} \mathrm{C}$ por 1 minuto e extensão a $72^{\circ} \mathrm{C}$ por 1 minuto.

\section{SSCP (Polimorfismo Conformacional de Fita Simples)}

Para que pudessem ser rastreados os prováveis polimorfismos o produto da PCR foi submetido à desnaturação ( $94^{\circ} \mathrm{C}$ por 5 minutos) e em seguida corridos em gel não desnaturante de poliacrilamida (49:1) com glicerol (5\%), por um período de 5 horas, a $250 \mathrm{~V}$ e $65 \mathrm{mM}$.

Após o tempo de corrida das amostras, as visualizações das bandas foram feitas por coloração com nitrato de prata, segundo protocolo em uso no Laboratório de Genética da PUCPR. 
Subseqüente, os géis foram acondicionados em papel celofane e armazenados.

\section{Resulta dos e Discussão}

Dentre o total de amostras inicialmente obtidas, apenas 52 puderam ser amplificadas e analisadas por SSCP.

Vários problemas foram observados durante as etapas do trabalho. Primeiramente, as amostras existentes na instituição de ensino e extraídas por salting-out não tiveram resultados positivos, onde nenhuma delas pôde ser amplificada. Acredita-se que este problema esteja associado à degradação das amostras em decorrência do tempo de estocagem (todas apresentavam mais de 5 anos de armazenagem) e uso contínuo em outras pesquisas, o que ocasionava constantes congelamentos e descongelamentos.

Descartadas estas amostras, iniciou-se a utilização de amostras contidas em papel filtro. Logo de imediato puderam-se observar resultados positivos (amostras amplificadas), embora em um primeiro instante ter havido a amplificação das amostras, isto não ocorreu durante todo o projeto. Provavelmente a não utilização de papel filtro específico corroborou com o insucesso das demais amplificações.

Poucos estudos foram realizados sobre a variabilidade genética da proteína lactoferrina, 0 que dificultou um melhor andamento do projeto e uma otimização das técnicas para a análise da variabilidade do gene.

Embora o espaço amostral final tenha sido significativamente menor que o amostral inicial, conseguiu-se observar 4 padrões diferentes para a LF. Dentre as 52 amostras analisadas, pode-se observar os padrões de 1, 2 ,3 e 4 bandas, respectivamente (figura 1).

Apesar de terem sido encontrados 4 padrões diferentes de bandas, não se pode afirmar a presença de 4 alelos e sim de apenas 2 , claramente existentes quando observados os padrões de 1 e 2 bandas (figura 2). Analisando os outros dois padrões, pode-se sugerir a presença de um terceiro alelo no padrão de 3 bandas ou talvez uma possível conformação secundária do alelo 1. 0 mesmo pode ser verdade para o padrão de 4 bandas, a presença de um quarto alelo ou ainda uma conformação secundária do alelo 2 (figura 2).
A partir da análise dos resultados percentuais obtidos dos padrões de bandas diferentes observadas (figuras 3 e 4), pôde-se constatar uma alta freqüência da expressão destes.

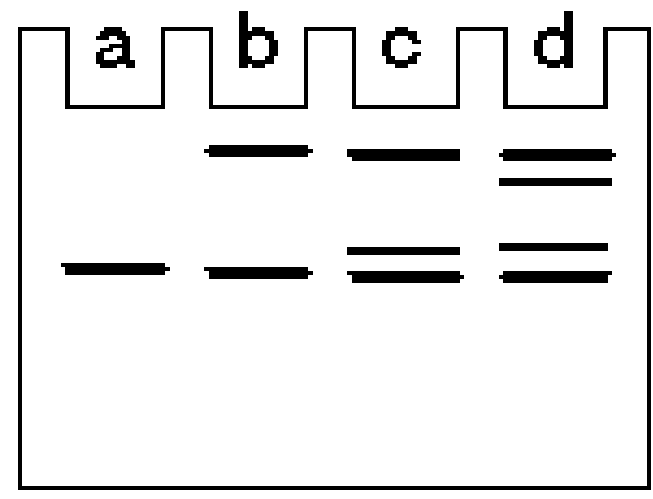

FIGURA 1. Representação dos Padrões de Bandas Obtidos por SSCP.

Nota: a.padrão com 1 banda; b.padrão com 2 bandas; c.padrão com 3 bandas; d. padrão com 4 bandas.

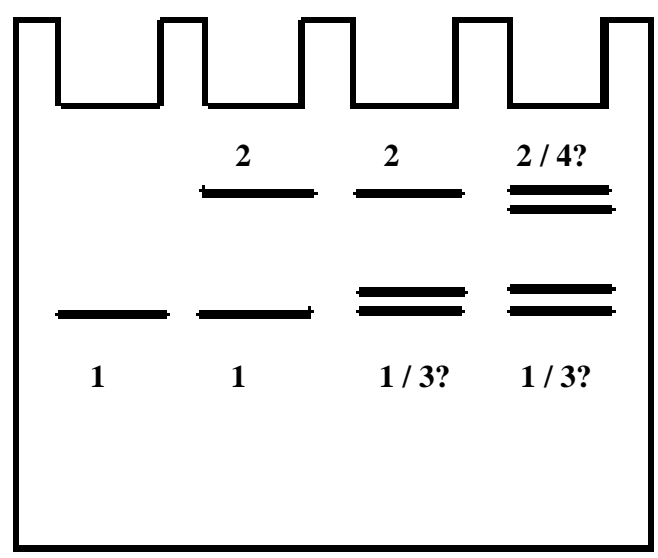

FIGURA 2. Esquema representativo dos possíveis alelos envolvidos nas mutações. Nota: 1 - alelo tipo $1 ; 2$ - alelo tipo 2; $1 /$ 3 ? - conformação secundária do alelo tipo 1, ou alelo tipo 3?; 2/4? - conformação secundária do alelo tipo 2, ou alelo tipo 4 ? 


\section{Distribuição dos Indivíduos pelo Número de Bandas Observadas}

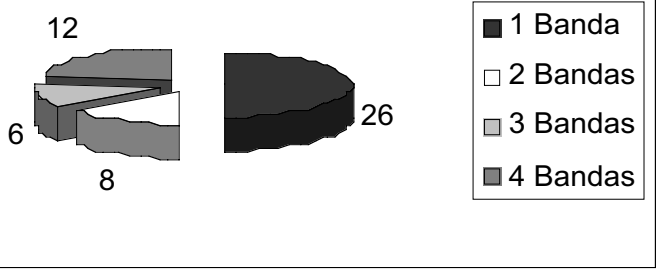

FIGURA 3. Gráfico da distribuição das bandas observadas pelo número de indivíduos.

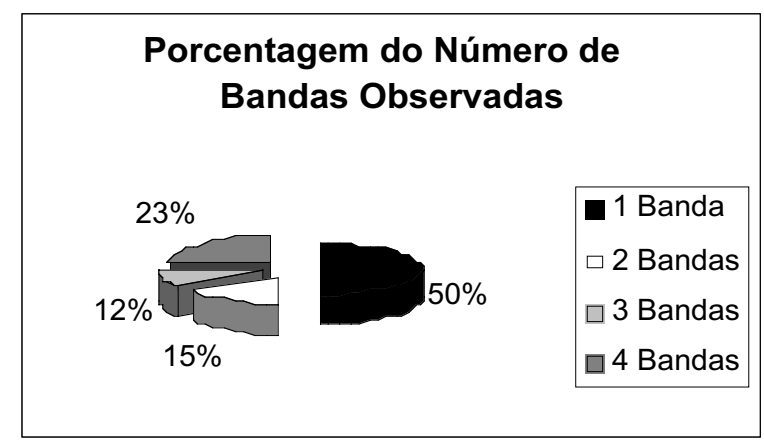

FIGURA 4. Gráfico da Porcentagem do número de bandas observadas.

É improvável que estes padrões estejam relacionados a algum tipo de doença, devido à alta expressão na população. Em um segundo caso, estes polimorfismos observados podem estar relacionados com doenças de quadro clínico leve. As doenças classificadas desta maneira não apresentam grandes proporções fenotípicas, assim seria possível que algumas destas variabilidades estivessem associadas a alguns tipos de doenças, porém por serem de pouca expressão fenotípica e sem gravidade, estes indivíduos não saberiam que as apresentam.

Embora algumas especulações a respeito de associações referentes aos padrões genotípicos encontrados para o gene da LF terem sido criadas, ainda se fazem necessários outros estudos, relacionando estes padrões a algumas doenças e à realização de outras amplificações, para que possa ser descartada a hipótese de que algumas das bandas visualizadas sejam decorrentes de artefatos.

\section{Agradecimentos}

Ao Dr. Ricardo Lehtonen, professor de Biologia da Universidade Federal do Paraná, que cedeu-nos espaço e assessoria para a conclusão da pesquisa.

\section{Referências}

1. Loesche WJ. Role of Streptococcus mutans in human dental decay. Microbiol Rev 1986, 50(4): 353-80.

2. Velliyagounder $\mathrm{K}$, Kaplan JB, Furgang D, Legarda D, Diamond G, Parkin RE, Fine DH. One of two lactoferrin variants exhibitis increased antibacterial and transcriptional activation activities and is associated with localized juvenile periodontitis. Infect Immun 2003, 71(11): 6141-47.

3. Weinberg ED. Iron and Infection. Microbiol Rev 1978, 42(1): 45-66.

4. Fillebeen C, Descamps L, Dehouck MP, Fenart L, Benaissa M, Spik G, Cecchelli R, Pierce A. Receptor-mediated transcystosis of lactoferrin through the blood-brain barrier. J Biol Chem 1999, 274(11): 7011-17.

5. Ellisson III RT, Giehl TJ, LaForce MC. Damage of the outer membrane of enteric gram-negative bacteria by lactoferrin and transferrin. Infect Immun 1988, 56(11): 2774-81.

6. Brock JH, Pickering MG, McDowall MC, Deacon AG. Role of antibody and enterobactin in controlling growth of Escherichia coli in human milk and acquisition of lactoferrin- and transferring-bound iron by Escherichia coli. Infect Immun 40(2): 453-59.

7. Broxmeyer HE. Lactoferrin acts an ia-like antigen-positive subpopulations of human monocytes ti inhibit production of colony stimulatory activity in vitro. J Clin Invest 1979, 64: 1717-20.

8. Oran JD, Reiter B. Inhibition of bacteria by lactoferrin and others iron-chelating agents. Biochim Biophys Acta 1968, 170(2): 351-65. 
9. Ambruso DR, Johnston RB. Lactoferrin Enhances hydroxyl radical production by human neutrophils, neutrophil particulate fractions, and an enzymatic generating system. J Clin Invest 1981, 67: 352-60.

10. Elass-Rochard E, Legrand D, Salmon V, Roseanu A, Trif M, Tobias PS, Mazurier J, Spik G. Lactoferrin Inhibits the endotoxin interaction with CD14 by competition with the lipopolysaccharide-binding protein. Infect Immun 1998, 66(2): 486-91.

11. Bals R. Epithelial antimicrobial peptides in host defense against infection. Respir Res 2000, 1: 141-50.

12. Wilson ME, Vorhies RW, Andersen KA, Britigan $B E$. Acquisition of iron from transferrin and lactoferrin by the protozoan Leishmania chagasi. Infect Immun 1994, 62(8): 3262-69.

13. Tenovuo J, Lumikari M, Soukkat T. Salivary lysoensyme, lactoferrin and peroxidases: antibacterial effects on carciogenic bactéria and clinical applications in preventive dentistry. PROC Finn Dent Soc 1991, 87(2): 197-208.
14. OMIN (150210). Disponivél em URL: http:// www.pubmed.com

15. Legrand D, Mazurier J, Aubert JP, LoucheuxLafebvre MH, Montreuil J, Spik G. Evidence for interactions between the $30 \mathrm{kDa} \mathrm{N}$ - and $50 \mathrm{kDa}$ C-terminal tryptic fragments of human lactotransferrin. Biochem J 1986, 236: 839-44.

16. Anderson BF, Baker HM, Dodson EJ, Nomis GE, Rumball SV, Waters JM, Baker EN. Structure of human lactoferrin at 3.2-A resolution. Proc Natl Acad Sci USA 1987, 84(7): 1769-73

17. Raskin S, Phillipis III JA, Krishnama MR, Vnemcak-Jones C, Parker RA, Rozov T, Cardieri JM, Marostica P, Abreu F, Giugliani R. DNA analysis of cystic fibrosis in Brazil by direct PCR amplification from Guthrie cards. Am J Med Genet 1993, 46(6): 665-69.

Recebido em / Received: June 9, 2005. Revisado em / Revised: August 16,2005. Aceito em / Accepted: September 19, 2005. 